\title{
O equilíbrio na aquisição do esquema corporal de crianças em idade escolar
}

Debora Rigon

Miriam Salete Wilk Wisniewski

CADERNO DE RESUMOS

FisiSenectus. Unochapecó Ano 1 - Edição especial - 2013 p. 120

Debora Rigon, acadêmica do curso de Fisioterapia da URI - campus de Erechim, debora.rigon@hotmail.com

\section{Resumo}

Introdução: Psicomotricidade é a ciência que tem como objeto de estudo o homem através de seu corpo em movimento e em relação ao seu meio interno e externo, relacionada ao processo de maturação neurológica, sendo o corpo a origem das aquisições cognitivas, afetivas e orgânicas. Sustenta-se por três conhecimentos básicos: o movimento, o intelecto e o afeto (SBP, 2011). Segundo Fonseca (1995), são sete os fatores psicomotores a serem adquiridos na infância: tonicidade, equilibração, lateralidade, esquema corporal, estruturação espaciotemporal, praxia ampla e praxia fina, que seguem um plano hierarquizado de aquisição neurológica, iniciado nos primeiros dias de vida uterina e que se completa aos sete anos, período em que formalmente as crianças, nas escolas, iniciam o desenvolvimento dos saberes cognitivos. A investigação do processo evolutivo da criança e a identificação de problemas relacionados ao seu desenvolvimento psicomotor possibilitam a intervenção precoce em atrasos evolutivos e a implementação de programas de estimulação para crianças com distúrbios de desenvolvimento, em risco, ou somente com a intenção de enriquecimento do ambiente estimulador. Objetivo: Identificar o perfil psicomotor de crianças com idade entre 6 e 7 anos, nos fatores: equilíbrio e esquema corporal; Comparar os fatores psicomotores: equilíbrio e esquema corporal, pré e pós-intervenção psicomotora; Correlacionar o fator psicomotor esquema corporal ao desempenho obtido no equilíbrio pós-intervenção psicomotora. Metodologia: Estudo do tipo exploratório descritivo, de abordagem qualiquantitativa, a ser realizado em uma Escola de Educação Básica no município de Erechim. A amostra será constituída por 20 crianças escolhidas aleatoriamente, de ambos os sexos, com idade entre 6 a 7 anos, cujos pais tenham autorizado a participação através de assinatura de termo de consentimento livre e esclarecido. A amostra será submetida a avaliação de dois fatores psicomotores: equilíbrio e esquema corporal através da Bateria Psicomotora. Após avaliação será realizada a intervenção psicomotora baseada em atividades de equilíbrio, totalizando 30 encontros semanais, duas vezes por semana, com duração de aproximadamente 40 minutos. Finalizando, as crianças serão reavaliadas, considerando os mesmos fatores psicomotores iniciais. Após a coleta dos dados, os mesmos serão analisados estatisticamente através do Teste t de Student, considerando nível de significância, 0,05\%. Para medir o grau de correlação entre as variáveis esquema corporal e equilíbrio, será utilizado o teste de correlação de Pearson. Considerações finais: Espera-se que os resultados possam apresentar as contribuiç̧ões que um programa de intervenção pautado em atividades de equilíbrio possam proporcionar sobre o esquema corporal dos escolares deste estudo.

\section{Palavras-chave}

Desempenho psicomotor. Saúde da criança. Intervenção precoce.

Monografia de Conclusão de Curso, em andamento. 